\title{
XXXII.-The Stable Dextrin of Starch Transformations, asul its Relation to the Maltodextrins and Soluble Starch.
}

By Horace T. Brown, LL.D., F.R.S., and J. H. Millar.

Content's.

I. Introduction

II. Separation and Purification of the Stable Dextrin . . . . . . . 317

III. Is the Stable Dextrin a Reducing Substance? . $\quad 322$

IV. Oxidation of the Stable Dextrin and Formation of Dextrinic Acid . . . . . . 325

V. Nitration and Subsequent Recovery of Dextrinic Acid . . . . . . . . 326

VI. Analysis of Calcium Salt of Dextrinic Acid . 328

VII. Hydrolysis of Dextrinic Acid with Oxalic Acid and Diastase . . . . . . 328

VIII. Hydrolysis of the Stable Dextrin with Oxalic A.cid and Diastase . . . . . . 330

IX. Generalisations and Conclusions . . . 331

\section{Introduction.}

Ir was shown by one of us and Heron in 1879 (Trans., 1879, 35, 596, that when gelatinised starch, or soluble starch, is hydrolysed with a little cold-water malt-extract at temperatures below $60^{\circ}$, the reaction proceeds with great rapidity until the mixed products of transformation show a cupric reduction corresponding to about 80 per cent. of

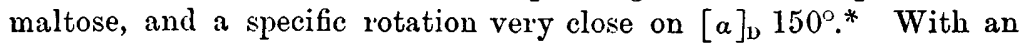
active diastase, this point may be reached in less than 5 minutes, and further change is comparatively very slow indeed.

* $\Lambda$ t ordinary temperatures, the specific rotatory power may be temporarily lower than this owing to the maltose being liberated in the birotatory state. (See Trans., $1895,67,309$. 
This fact has been referred to many times in our papers, and was illustrated in the 1879 paper by a series of time curves, and again in the same manner in a paper on amylodextrin published in 1889 (Trans., 55, 457).

These values of $[a]_{D} 150$ and $R 80$ ma.rk, in fact, a detnnite resting point in the reaction, beyond which it is difficult to push it, unless a considerable amount of time is allowed.

That the cessation of action is due neither to the weakening of the enzyme nor to the action being a reversible one, ${ }^{*}$ may be readily shown in a variety of ways. For instance, (1) the addition of more enzyme has no appreciable effect in hastening the very slow subsequent change after the resting point has been reached; (2) if more gelatinised starch or soluble starch is added to the solution, it is speedily brought to the same condition of optical activity and reducing power; (3) when a complete or partial separation of the maltose is effected by suitable means, as by fermentation or fractionation with alcohol, the residual dextrin shows the same resistance to further hydrolysis with diastase as do the mixed products which have attained the resting stage.

In the 1879 paper (loc. cit.), it was also shown that, if we assume the whole of the reducing substance to be maltose, the resting point of the reaction corresponding to $[a]_{D} 150^{\circ}$ and $R 80$ agrees very closely with the view that the starch has been hydrolysed according to the following empirical equation,

$$
\underset{\substack{12 \\ \text { Starch. }}}{10 \mathrm{C}_{20} \mathrm{O}_{10}}+8 \mathrm{H}_{2} \mathrm{O}=\underset{\text { Nlaltose. }}{8 \mathrm{C}_{12} \mathrm{H}_{22} \mathrm{O}_{11}}+\underset{\text { Dextrin. }}{2 \mathrm{C}_{12} \mathrm{H}_{20} \mathrm{O}_{10}}
$$

which requires 80.8 per cent. of maltose in the products of transformation.

This was the so-called 'No. 8 equation,' which at that time was supposed to represent only one of several other halting points in the hydrolysis. We are now of opinion that this well-marked resting stage, corresponding to $[\alpha]_{\mathrm{D}} 150, \mathrm{R} 80$, is the only one which admits, with certainty, of being expressed by any definite equation.

From the solution of the starch products which have been allowed to reach the above-mentioned point, crystallisable maltose can readily be prepared by extraction with alcohol of 80 per cent., or the maltose can be fermented out by yeast. By either of these methods of treatment, by far the greater part of the reducing substance may be removed, and in this respect these complete starch transformations stand in strong contrast with those in which the resting stage has not

* By this we do not mean to imply a denial that the action may not be to some extent a reversible one, but only that this particular effect cannot bo due to reversion. 
been fully attained, since, in all incomplete conversions, the reducing constituent is not present wholly as crystallisable, fermentable maltose, but, in part, at any rate, as maltodextrins. Complete and incomplete conversions also differ from one another in their behaviour towards phenylhydrazine. If the transformation products have reached the resting stage corresponding to $[a]_{\mathrm{D}} 150, \mathrm{R} 80$, the yield and purity of maltosazone is much greater than is obtained from a proportional amount of an incomplete transformation which might be assumed, from its reducing power only, to contain an equal amount of maltose. Indeed, all the available facts bear out the supposition that in a complete conversion which has attained the resting stage, the greater part, if not the whole, of the reducing power is due to free, crystallisable, and readily fermentable maltose.

Such a solution, besides maltose, contains an achroodextrin, which is precipitable by alcohol of $80-85$ per cent. This dextrin, amounting to about $20 \mathrm{per}$ cent. of the starch originally taken, is attacked only with diffeulty by diastase, and differs in this respect from all the intermediate dextrinous products, amongst which is the maltodextrin which has been the subject of a previous paper.

We have submitted this stable dextrin to a careful re-examination during the past two years, and the present paper deals with our most recent conclusions with regard to its nature, properties, and constitution.

The difficulties of obtaining the stable dextrin in a state of purity are considerable, and even greater than they are in the case of maltodextrin. This arises from the fact that the process of treatment with alcohol necessarily tends to concentrate in the final insoluble product all impurities pre-existent in the starch and the transforming agent, which happen to be insoluble in the lowest strength of alcohol used in the separation.

If fermentation has also been employed, there is the additional risk of introducing small amounts of nitrogenous impurities, and also some of the non-volatile products of fermentation, although the latter are, for the most part, removable by the subsequent treatment with alcohol.

The actual amount of such impurities, which may amount to 2-3 per cent., can be determined with a close approximation to accuracy by submitting the separated dextrin to the standard methods of acid hydrolysis described in the previous paper (p. 305).

\section{Separation and Purification of the Stable Dextrin.}

In these experiments, we always commenced with from 2000 to 3000 grams of well-washed potato starch, which was brought into 
solution with from 16 to 20 litres of water by successive gelatinisations and liquefactions, in the manner described in our previous paper on maltodextrin (this vol., p. 288). We thus obtained the starch solids, for the final conversion, at a concentration of from 12 to 15 per cent. The preliminary conversions at $65-70^{\circ}$ were allowed to go sufficiently far to prevent any of the higher starch transformation products coming out of solution when the temperature was reduced to $15-20^{\circ}$. The completion of the conversion down to the 'resting point,' corresponding to $[a]_{\mathrm{D}} 150^{\circ}, \mathrm{R} 80$, was then carried out at the ordinary temperature, with the aid of coldwater malt-extract, made from a very diastasic air-dried malt. This conversion sometimes lasted for two days * or more, the object being to select the best conditions for producing a low conversion, with the employment of the minimum amount of malt-extract. The importance of this condition is rendered evident by what we have already said about the concentration of impurities on the dextrin during the subsequent processes of its extraction.

The actual amount of 'normal' $\dagger$ malt extract required was from 3 to 6 c.c. of the extract per 100 c.c. of a solution containing from 9 to 15 grams of starch products. This is equal to from 0.3 to 0.4 c.c. of extract per gram of starch converted, and represents about the minimum amount which can be used for these complete conversions. The actual amount of solids introduced with the malt-extract represents about 3.5 per cent. of the starch used, but by far the greater part of these solids are separable by alcohol of from 75-90 per cent., and are removed in the processes of purification to which the dextrin is submitted.

After the conversion had been run down to the desired point, the solution, filtered from a certain amount of 'starch-cellulose,' which always separates during starch transformations made in the cold, was evaporated to a thick syrup. The process of separation was then commenced; this consisted of fractionation with alcohol of various degrees of strength with occasional recourse to fermentation. The treatment with alcohol was varied in every conceivable manner.

It would be tedious and unprofitable to give anything but a mere sketch of the process, since, at this stage, it did not differ materially from similar methods we have frequently described before, except as regards the number of operations and the length of time required, often amounting to several months for each experiment.

* The solution was occasionally sterilised, with the further adlition of malt extract.

$\dagger$ 'Normal' malt extract is obtained by digesting finely divided malt (air dried) with $2 \cdot 5$ times its weight of cold water, and filtering after 6 hours. 
We will briefly describe the course of one experiment, which is typical of all.

A conversion of 2400 grams of starch which had been run down to the 'resting stage' and evaporated to a syrup was treated in the first place with 7 litres of hot alcohol of 90 per cent.," the strength of the alcohol in the mixture being $75-80$ per cent.

About 200 grams of dextrin separated. The alcoholic solution, poured off when cold, was distilled, and the syrupy residue poured into 6 litres of boiling spirit of 95.5 per cent., and digested for some time. The second dextrinous residue thus obtained was further digested with 85 per cent. spirit, the insoluble portion being added to the original residue of 200 grams. The alcoholic solutions on distillation yielded a syrup from which maltose readily crystallised.

The combined dextrinous portions, amounting to 660 grams, now contained only 42 per cent. of maltose, as against 80 per cent. in the original starch transformation products. This crude dextrin was dissolved in 6 litres of water, and the solution, having a sp. gr. of 1042.6, was set to ferment with 15 grams of washed and pressed yeast. During the progress of the fermentation, which lasted for 10 days, an examination of the solution was made from time to time, and it was shown that, whilst the specific rotatory power of the unfermented matter steadily increased, the optical properties of the portions fermented at any stage corresponded with those of maltose.

The fermented solution, which now gave only a trace of insoluble osazone on treatment with phenylhydrazine, was evaporated to remove alcohol. The specific rotatory power of the residue was $[a]_{D} 182.5^{\circ}$.

In order to remove any trace of maltodextrin, the solution, made up to sp. gr. 1043, was now once more treated for 2 hours at $50^{\circ}$ with 40 c.c. of a very active malt extract. It was then once more heated to the boiling point, cooled, and again set to ferment with 11 grams of washed yeast for 5 days, during which time 14.04 grams of fermentable substance disappeared, which represents about 3.0 per cent. of the 540 grams of the crude dextrin. The optical properties of this fermentable substance were again found, by the usual process of fractional fermentation, to correspond with those of maltose.

Two precipitations were then made with 85 per cent. alcohol, and the dextrin obtained was submitted to nine successive extractions with boiling alcohol, each extraction lasting for a day or more, the mixture being frequently agitated. The first six of these extractions were made with alcohol of 85 per cent., and the other two with alcohol of 80 per cent. The weights and specific rotatory powers of the matter extracted, and the specific rotatory power of the residual dextrin after each extraction, were determined.

* Throughout the paper, the percentages of alcohol are expressed by colume. 
The results of the nine successive treatments at this stage are here tabulated.

The amount of crude dextrin at the commencement was 492 grams.

TABLE I.

\begin{tabular}{|c|c|c|c|}
\hline \multirow{2}{*}{ No. of fraction. } & \multicolumn{2}{|c|}{ Extracted with alcohol. } & \multirow{2}{*}{$\begin{array}{c}\text { Residual dextrin. } \\
{[a]^{\mathrm{D}} .}\end{array}$} \\
\hline & Weight. & {$[a]^{\mathrm{D}}$} & \\
\hline 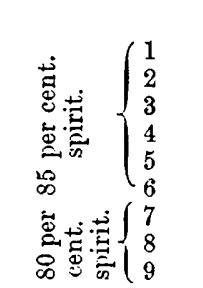 & $\begin{array}{r}\text { Grams. } \\
10 \cdot 66 \\
8 \cdot 14 \\
9 \cdot 39 \\
9 \cdot 63 \\
2 \cdot 51 \\
7 \cdot 07 \\
22 \cdot 12 \\
22 \cdot 34 \\
17 \cdot 11\end{array}$ & $\begin{array}{l}115 \cdot 7^{\circ *} \\
127 \cdot 3 \\
145 \cdot 7 \\
166 \cdot 3 \\
167 \cdot 1 \\
168 \cdot 2 \\
174 \cdot 6 \\
166 \cdot 9 \\
177 \cdot 7\end{array}$ & $\begin{array}{l}-\overline{185 \cdot 3^{\circ}} \\
186 \cdot 9 \\
186 \cdot 8 \\
186 \cdot 7 \\
188 \cdot 2 \\
187 \cdot 5 \\
\overline{186 \cdot 8}\end{array}$ \\
\hline
\end{tabular}

* These extractions contained the non-volatile products of fermentation and the sugar's of the malt-extract.

It was evident that the method of separation adopted up to this point had practically reached the experimental limits, so a different plan of treatment was now adopted.

The dextrinous residue, after the ninth treatment, amounting to 383 grams of substance with an $[a]_{\mathrm{D}}$ of $186^{\circ} 8^{\circ}$, was dissolved in 1000 c.c. of water, and cold alcohol of 85.5 per cent. was gradually added, until precipitation just commenced. The precipitate containing albuminous matter was rejected. Alcohol of 85.5 per cent. was again added with constant agitation, until about one-third of the dextrin was thrown down. This is fraction A, and it was separately treated by dissolving it in its own weight of water, and precipitating in two fractions, $A_{1}$ and $A_{2}$, by the further addition of 85 per cent. spirit.

These fractions had the following properties.

$$
\begin{array}{llc}
\mathbf{A}_{1} & {[\alpha]_{\mathbf{D}} 193 \cdot 1} & \mathrm{R} 5 \cdot 6 \\
\mathbf{A}_{2} & {[\alpha]_{\mathrm{D}} 193 \cdot 0} & -
\end{array}
$$

The clear solution from $\mathbf{A}$ was again precipitated in the cold with alcohol. On heating, the precipitate redissolved, but was again thrown out on cooling-this is fraction B. After the removal of the precipitate, the liquid was increased in alcoholic strength, in the first place to 85 per cent., and in the second to 95 per cent., the fractions thus obtained being $\mathrm{C}$ and $\mathrm{D}$. The final mother liquor from $\mathrm{D}$ was mixed with that from $\mathrm{A}_{2}$, and the 55 grams constituting fraction $\mathrm{E}$ were 
freed from alcohol and separated into two parts, $E_{1}$ and $E_{2}$, with 95 per cent. alcohol. These latter fractions had the following specifie rotatory power.

$$
\begin{array}{rrr}
\text { Fraction } \mathrm{B} & {[\alpha]_{\mathrm{D}} 192 \cdot 1^{\circ}} & \text { Fraction } \mathrm{E}[\alpha]_{\mathrm{D}} 184.9^{\circ} \\
\mathrm{C} & {[\alpha]_{\mathrm{D}} 190 \cdot 8} & \mathrm{E}_{1}[\alpha]_{\mathrm{D}} 186 \cdot 5 \\
\mathrm{D} & {[\alpha]_{\mathrm{D}} 189 \cdot 0} & \mathrm{E}_{2}[\alpha]_{\mathrm{D}} 179 \cdot 7
\end{array}
$$

It is clear from the above that the dextrin which could not be further separated by the nine treatments with alcohol described in Table I has given way to the modifications in the alcohol treatment just described, products being obtained amongst the least soluble portions with specific rotatory powers as high as $[a]_{\mathrm{D}} 193 \cdot 0^{\circ}$.

The above fractions $A_{1}, A_{2}, B, C$, and $D$, with rotatory powers of from $[a]_{\mathrm{D}} 189 \cdot 0$ to $[a]_{\mathrm{D}} 193 \cdot 1$ were now united and subjected to still further treatment.

After being evaporated to a thick syrup, they were gradually treated with 2 litres of hot 86 per cent. alcohol ; after digestion for 6 hours, the alcoholic solution, when cold, was poured off, and the properties of the residue, and those of the small quantity of extracted matter, were examined. These were as follows.

$$
\begin{array}{ll}
\text { Dextrinous residue.............. } & {[a]_{\mathrm{D}} 192 \cdot 7^{\circ}} \\
\text { Portion soluble in alcohol... } & {[a]_{\mathrm{D}} 183.6}
\end{array}
$$

This process was repeated twice more, and the dextrin, which had now been reduced to about 200 grams, was obtained with a specific rotatory power of $[a]_{\mathrm{D}} 192 \cdot 0^{\circ}$.

We now once more resorted to fractionation. The 200 grams of dextrin were dissolved in 500 c.c. of water, and 500 c.c. of alcohol added in the cold ; the addition of 100 c.c. more of 96 per cent. alcohol brought down fraction $\mathrm{F}$; this, when redissolved in 200 c.c. of water and again treated with 250 c.c. of 96 per cent. alcohol, gave a precipitate which, by further similar treatment, was resolved into fractions $F_{1}, F_{3}$, and $F_{4}$, having the following optical and reducing properties.

$\begin{array}{lcc} & {[\alpha]_{\text {. }}} & \mathbf{R .} \\ \mathbf{F}_{1} & 194 \cdot 7^{\circ} & 5 \cdot 9 \\ \mathbf{F}_{3} & 195 \cdot 6 & 5 \cdot 9 \\ \mathbf{F}_{4} & 195 \cdot 4 & -\end{array}$

It must be remembered that, in the protracted and laborious treatment of separation, which ishere only described in a very condensed form, every conceivable variation of treatment with alcohol was adopted, whilst the process was further supplemented by occasional treatment with diastase to break down any maltodextrin which might remain adherent to the product, and also by employing fermentation to assist in the elimination of the maltose. 
In all similar experiments, no matter how long the alcoholic fractionation may have been continued, we have always obtained the same final result. A point is ultimately reached, sometimes comparatively speedily, when no further change takes place in the properties of the separated dextrin. This is marked by the product assuming optical and reducing properties corresponding to

$$
\begin{array}{cc}
{[a]_{\mathrm{D}}} & 195-196^{\circ} \\
\mathrm{R} \quad 5 \cdot 5-5.9
\end{array}
$$

Such a product is, however, never quite free from ash, which amounts to 0.3 to 0.5 per cent. of the dry weight, and it also contains a trace of nitrogen corresponding to about 0.2 per cent. of albuminoids. Hence the above values of $[a]_{D}$ and $R$ are slightly lower than those corresponding to the pure carbohydrate; the error introduced from this cause does not, however, exceed more than $2^{\circ}$ in the specific rotatory power, and will have no appreciable effect on the value of $R$.

Prepared in this manner, this dextrin is obtained as a white, amorphous, gummy substance, soluble in water to any extent, and completely separable from its aqueous solutions in the cold by alcohol of 80 per cent., which brings it down as a waxy solid with a silky lustre.

Dried at $100^{\circ}$ in a vacuum over phosphoric anhydride, it has a divisor of 3.995 for a solution density of 1054.49 .

One of the chief characteristics of this dextrin, prepared from starch conversions which have attained the 'resting stage,' is the relative difficulty with which it is attacked by diastase, as compared with the small power of resistance exhibited by the intermediate products. The mode in which it breaks down under the agency of dilute acids, and the long continued action of diastase, will be described later on.

\section{Is the Stable Dextrin a Reducing Substance?}

We have already stated that the final product obtained by protracted treatment with alcohol, assisted by fermentation, always possesses a reducing power of about $R 5 \cdot 5$, and we have now to consider whether this is inherent to the dextrin itself, or whether it may not, after all, be due to an admixture of from 10 to 15 per cent. of compounds of the maltodextrin class which have persistently adhered to it through all the long processes of treatment to which it has been subjected. The reducing power certainly cannot be due to maltose itself, since the purified dextrin gives no trace of maltosazone when treated with phenylhydraaine, neither does it contain any substance directly fermentable with yeast.

If the stable dextrin in a state of purity is a non-reducing substance, 
it is possible to deduce its optical properties from an analysis of the mixed products of a starch transformation which has been carried down to the 'resting stage.' With the improved methods of analysis which we have described in a previous paper (Trans., 1897, 71, 72), it is possible to determine this value with considerable accuracy, for under these conditions complete corrections can be made for the transforming agent (malt-extract) employed, and for the small amount of ash existing in the original starch. After fractionation, these corrections cannot, of course, be applied with the same degree of accuracy.

We have made two such experiments for the determination of the specific rotatory power of the stable dextrin, on the assumption that it is non-reducing.

It is necessary, in the first place, to determine very exactly the total weight of the starch products per 100 c.c. of the liquid after complete transformation. This is effected by correcting the specific gravity for that due to the malt-extract, and then employing the particular 'divisor' corresponding to the phase of transformation and the concentration of the solution.

The 'divisor curve' for a transformation corresponding to $[a]_{D} 150$, R 80 has been accurately determined for concentrations of from $2 \cdot 4$ to $22 \cdot 3$ per cent. of solids, and will be found at p. 80 of our previous paper on "Experimental Methods" (Trans., 1897, 71, 72). In such experiments as we are describing, where the highest degree of accuracy is necessary, a further small correction was necessary for the 0.2 per cent. of ash which the original starch contained.*

The amouut of apparent maltose per 100 c.c. was then determined from the cupric reduction, due correction being, of course, made in all cases for the reduction due to malt-extract.

The amount of rotation corresponding to the maltose was then calculated from the known optical constants of the maltose at the particular concentration, and the value thus obtained was deducted from the total (corrected) optical activity of the original solution. The remainder represented the rotation due to the dextrin, the amount of which was also known by subtracting the known amount of maltose from the total (corrected) starch solids per 100 c.c.

We thus have all the elements necessary for the calculation of the specific rotatory power of the dextrin.

To ensure the greatest possible accuracy, the volumes of the liquid were deduced from weighings and densities, and the cupric reductions, several times repeated, were also made on weighed amounts of the solutions.

* This correction ouly affects the divisor in the third decimal place. For instance, the divisor from the curve being 3.958 for sl. gr. 1033.61 , becomes, when corrected for 0.2 per cent. of ash, 3.954 . 
In the first experiment, the mixed transformation products corressponded to $[a]_{\mathrm{D}} 150 \cdot 3, \mathrm{R} 79 \cdot 6$, and in the second to $[a]_{\mathrm{D}} 150 \cdot 4$, R 79.0.

The estimated specific rotatory power of the stable dextrin, assuming it to be non-reducing, came out as follows.

$$
\left.\begin{array}{ll}
\text { (1) }[a]_{\mathrm{D}} 201 \cdot 8^{\circ} \\
\text { (2) }[a]_{\mathrm{D}} 200 \cdot 0
\end{array}\right\} \begin{aligned}
& \text { Hean. } \\
& 200 \cdot 9^{\circ} .
\end{aligned}
$$

The properties of the dextrin which we obtained by continuous fractional treatment of the starch transformation products corresponded, as we have seen, to $R 5.5$ to 5.9 and $[a]_{\mathrm{D}} 195^{\circ}$ to $196^{\circ}$, with a possible error of $+2^{\circ}$. These properties are quite consistent with a mixture of 94.5 per cent. of a non-reducing dextrin with an $[a]_{\mathrm{D}} 200.9^{\circ}$, and 5.5 per cent. of maltose or its equivalent of maltorlextrin. Theoptical properties of such a mixture would correspond to $[a]_{\mathrm{D}} 197 \cdot 4^{\circ}$. We are, however, by no means justified in concluding that the dextrin obtained really consists of such a mixture, and must seek further evidence in other directions.

In the paper of 1885 on the "Non-Crystallisable Products of Starch Transformation," by one of us and Morris (loc. cit.), a process was described by which the residual reducing power of dextrins, previously separated by alcoholic fractionation, could be completely destroyed, and the apparently unaltered dextrin recovered in a non-reducing state. This method consisted in acting on the dextrin with Knapp's mercuric cyanide solution, and subsequently acidifying with hydrochloric acid and separating the mercury with hydrogen sulphide, the dextrin being afterwards separated from the filtrate by precipitation with alcohol. Since the optical properties of the dextrins were somewhat increased by this process, and their behaviour under hydrolysis with diastase was apparently unaltered, it was believed that a separation had been effected between the dextrin and the substance to which it originally owed its reducing power.

In 1890, Scheibler and Mittelmeier, in a valuable and highly suggestive paper on starch products (Ber., 1890, 23, 3060), objected to this method on the ground that, if the dextrin were in itself a reducing substance, its aldehydic group would necessarily be oxidised, and that the resulting product would be an acid, and not the original unaltered dextrin. Unfortunately, the value of the experimental portion of the paper is much lessened by the fact that Scheibler and Mittelmeier made use of a commercial dextrin, which from their description must have been a torrefuction product of starch, at all times a very indeterminate substance, whose nature and relation to the dextrins of starch transformations has never been worked out. 
Nevertheless, the criticism of the method we employed to destroy the reducing power is perfectly just and well founded, as will be seen by a perusal of our recent paper on maltodextrin (this vol., p. 286), which contains the first experimental proof that a reducing starch product can give rise, on oxidation, to well-defined polysaccharide acids. It was the fact that these complex acids have such feeble acid properties, and resemble the parent substance so closely in optical properties and in their behaviour towards diastase, which caused us to overlook their formation in our work of ten years ago.

In the light of this work on maltodextrin, it appeared to us that the question whether the reducing power of $R 5.5$ possessed by the stable dextrin after repeated treatment is really in herent to the dextrin molecule, and is not due to admixture with something else, ought to be settled by oxidising the dextrin with mercuric oxide and baryta to the point of disappearance of its reducing power, and then once more fractionating the product. If the reducing power is due to a foreign substance, it is this alone which will be oxidised, and the acid or acids so formed ought to be separable from the dextrin which will be left as a neutral substance. If, on the other hand, the reducing power is inherent to the dextrin molecule, we ought to obtain a complex 'dextrinic acid' which will not give way to fractionation.

We have carried out this experiment several times with results which, we think, leave no doubt as to which supposition is correct.

\section{Oxidation of the Stable Dextrin and Formation of Dextrinic Acid.}

A preparation of the stable dextrin with $[a]_{\mathrm{D}} 195 \cdot 0, \mathrm{R} 5 \cdot 5$ was oxidised with mercuric oxide and barium hydroxide under the conditions employed for the oxidation of maltodextrin (this vol., p. 293). It was found that 70 grams of the dextrin with an excess of mercuric oxide required the gradual addition of 4.27 grams of crystallised barium hydroxide, $\mathrm{Ba}(\mathrm{OH})_{2}+8 \mathrm{H}_{2} \mathrm{O}$, to completely destroy its power of reducing Fehling's solution.

After filtration, the solution, slightly acidified with sulphuric acid, was again filtered, and the product was recovered by several precipitations with alcohol of 80 per cent. At this point, the oxidised dextrin had a specific rotatory power of $[a]_{\mathrm{D}} 192 \cdot 5^{\circ}$.

It was then partially precipitated three times successively with alcohol of 75,84 , and 85 per cent. The properties of the several fractions were 


$\begin{array}{lll} & {[a]_{\mathrm{p} .}} & \text { R. } \\ \text { 1. } & 193 \cdot 2 & 0 \\ 2 & 192 \cdot 0 & 0 \\ \text { 3. } & 192 \cdot 0 & 0\end{array}$

Although quite free from sulphuric acid, the solutions were distinctly acid to test paper.

It was now attempted to split this oxidised dextrin further by dissolving it in 50 per cent. alcohol and fractionally precipitating with a 5 per cent. solution of barium hydroxide in 50 per cent. methylic alcohol; the precipitated barium compounds were then separately treated, first with carbonic anhydride, and afterwards with dilute sulphuric acid in the cold, the oxidised dextrin being recovered from the filtrate by precipitation with alcohol.

The products thus obtained had specific rotatory powers varying only between $[a]_{\mathrm{D}} 193 \cdot 2^{\circ}$ and $[a]_{\mathrm{V}} 193 \cdot 6^{\circ} \mathrm{R} 0$. They were quite dextrinous in their physical characters, but all had a very distinct cuid reaction, from which the parent dextrin was quite free.

The oxidised dextrin, which we shall in future refer to as dextrinic acid, when dried in a vacuum over phosphoric anhydride, gave a divisor of 4.000 for a solution density of 1039.0 . It was not quite free from ash, so at this stage it was not found practicable to determine its molecular weight from its barium or calcium salt.

On hydrolysis with oxalic acid, ${ }^{*} 100$ parts of dextrinic acid yielded 105.9 parts of glucose, as against 108.8 parts yielded by the original dextrin (vide infia).

\section{Nitration and Subsequent Recovery of Dextrinic Acid.}

We have shown in a previous paper (this vol., p. 310) that when the stable dextrin is nitrated, the nitrate, on treatment with ammonium sulphide, yields a non-reducing substance with acid properties, not the original dextrin from which we started. We have found, however, that the dextrinic acid which is obtained by the oxidation of the dextrin with mercuric oxide and baryta is itself capable of nitration, and that the dextrinic acid can be readily regenerated from the nitrate in the usual manner, and with all its properties unchanged.

By this process, we are able to obtain the dextrinic acid quite free from ash, and consequently in a state suitable for the examination of its salts.

* The standard time of hydrolysis of 14 hours was not found sufficient to completely hydrolyse the dextrinic acid, which required 24 hours treatment under the conditions deseribed in the Appendix to our paper ou maltodextrin (this vol., p. 305). 
A specimen of dextrinic acid with an optical activity of $[a]_{1} 193^{\circ}$, and yielding 105.9 per cent. of glucose on complete hydrolysis with oxalic acid, was obtained as a thick syrup on concentrating its solution to the atmost on the water-bath. It was then mixed in the cold with ten times its weight of strong nitric acid, sp. gr. 1·4, and the nitrate thus formed was precipitated by strong sulphuric acid and subsequent dilution with water in the usual manner, the temperature being maintained as low as possible by immersing the vessel in ice cold water. The nitrate, after being well washed with water, was dissolved in glacial acetic acid and filtered; water added to this solution again threw out the nitrate, which was once more dissolved in acetic acid and reprecipitated. This operation was twice repeated, and the nitrate was then treated with ammonium sulphide; the recovered dextrinic acid was completely freed from ammonium salts by repeated precipitations with alcohol of 95 per cent., seven or eight such treatments generally being necessary before the Nessler test ceased to give a reaction. It was finally obtained in a state of purity, and quite free from ash, as a white, amorphous substance having feeble but distinct acid properties, and with a specific rotatory power corresponding to $[a]_{\mathrm{D}} 193.7^{\circ}$ and $\mathrm{R} 0$ against $[a]_{\mathrm{D}} 193.0^{\circ}$ of the original acid before nitration. After completely drying in a vacuum at $100^{\circ}$ over phosphoric anhydride, its divisor for a solution density of $1040 \cdot 36$ was found to be $4 \cdot 005$.

On complete hydrolysis with oxalic acid, it yielded 106.2 per cent. of glucose, against $105 \cdot 9$ given by the original dextrinic acid before nitration.

This experiment is an important one, not ouly in showing that the product recovered from the nitrated dextrinic acid is identical with the dextrinic acid before nitration, but also in showing that the acid properties of the oxidised dextrin cannot be due to the accidental admixture of other acids produced by the oxidation of a reducing carbohydrate present in the original dextrin. Were this the case, we should have to assume that the acids proceeding from this reducing carbohydrate not only persistently adhere to the dextrin during the repeated fractionations of dextrinic acid itself, but that even the process of nitration, fractionation of the nitrate, and the subsequent processes of recovery have also been incapable of effecting differentiation.

In the face of all this evidence, we think it can no longer be doubted that the carboxylic constituent of the oxidised dextrin really forms part of the molecular complex constituting dextrinic acid. To admit this fact is, of cour'se, to admit that the aldehydic or ketonic portion of the original dextrin, to which it owes its reducing power of $R 5 \cdot 5$, is also part of the molecular complex of the stable dextrin. 


\section{Analysis of the Calcium Salt of Dextrinic Acid.}

We have already stated that dextrinic acid possesses only very feeble, although well-marked, acid properties. It readily forms barium and calcium salts on boiling the acid with the respective carbonates, and these salts can be precipitated from the solution by dilute alcohol. They are readily soluble in water, but like the cor. responding derivatives of the maltodextrinic acids, they cannot be obtained in the crystallised form.

Owing to its complexity and feeble basicity, the dextrinic acid must be absolutely free from ash before it can be used for the preparation of its salts, otherwise their composition could not be even approximately determined.

The process of nitration of the acid and its subsequent regeneration from the nitrate fortunately enables us to prepare the dextrinic acid in this state and in a high degree of purity.

An analysis of the calcium salt after most careful preparation in this manner shows that it contains 0.29 per cent. of calcium.

\section{Hydrolysis of Dextrinic Acid with Oxalic Acid and Diastase.}

$W_{\theta}$ have already seen that when free dextrinic acid is completely hydrolysed with oxalic acid, the main product is glucose, which amounted in one experiment to 105.9 per cent. and in another to 106.2 per cent. The hydrolysis of the calcium salt in a similar manner was found to produce $107 \cdot 2$ per cent. of glucose on the dry salt.

It was always found in such experiments that, besides glucose, the complete hydrolysis gave rise to a small quantity of an acid of low molecular weight, the production of this final acid being strictly analogous to that of the $\mathrm{C}_{5}$-acid when the maltodextrinic acids are hydrolysed, or to that of gluconic acid when maltobionic acid or its salts are treated with dilute acids.

The large yield of glucose in the case of the dextrinic acid hydrolysis clearly shows that the carboxyl portion of the original complex must bear a very small relation to the total molecule, a result which is also quite in accord with the small reducing power of the dextrin from which the dextrinic acid has been derived.

Since we could not expect more than a 25 per cent. yield of the final acid, it was necessary to hydrolyse a considerable quantity of the dextrinic acid in order to obtain a sufficient quantity of this substance to admit of a study of its properties.

In order to see if it were gluconic acid, the mixed products from the hydrolysis were fermented with yeast, and the residue, after 
evaporation and treatment with calcium carbonate, was evaporated with alcohol and fractionated in such a manner as to separate any trace of calcium gluconate. No evidence of its existence could be obtained, although it had been shown in preliminary experiments that even an extremely small quantity of previously added calcium gluconate could be recovered in a crystalline form by the method adopted.

A sufficient quantity of the final acid for complete examination was prepared by completely hydrolysing 29 grams of dextrinic acid by heating it with a 2.5 per cent. solution of oxalic acid for 23 hours at $100^{\circ}$. The solution of the hydrolysed products, after treatment with calcium carbonate, was filtered and evaporated to the thickest possible syrup, which was then repeatedly extracted with hot 95 per cent. alcohol to remove the glucose.*

The residual calcium salt was redissolved in a small quantity of water, filtered, and again thrown down with alcohol; at this stage, the salt which was evidently still impure, contained 9.0 per cent. of calcium. After several further treatments of a similar kind, and a partial fractionation with alcohol, the salt was obtained with constant properties. The following results were obtained on analysis.

$\begin{array}{lcccc} & \text { Carbon. } & \text { Hydrogen. } & \text { Oxygen. } & \text { Calcium. } \\ \text { Calculated for }\left(\mathrm{C}_{5} \mathrm{H}_{6} \mathrm{O}_{6}\right)_{2} \mathrm{Ca} \ldots & 32 \cdot 4 & 4 \cdot 9 & 51 \cdot 8 & 10 \cdot 8 \\ \text { Found } \ldots \ldots \ldots \ldots \ldots \ldots \ldots \ldots \ldots & 32 \cdot 1 & 5 \cdot 3 & 52 \cdot 0 & 10 \cdot 56\end{array}$

The salt corresponds in composition and general properties with the final $\mathrm{C}_{5}$-acid which we obtained by complete acid hydrolysis of the two maltodextrinic acids, and also with the acid obtained by the oxidation of maltose with mercuric oxide and subsequent hydrolysis of the product (this vol., p. 296).

Dextrinic acid and its salts, unlike maltodextrinic acid $\mathbf{A}$, are but very slowly influenced by diastase. A marked action can, however, be detected if the digestion with malt extract in the cold is allowed to go on for several days, or if the amount of diastase used is relatively large, and the action is carried on for 48 hours or so at $50-60^{\circ}$.

The product of hydrolysis in this case is a mixture of maltose and glucose, a fact which will be further considered in the next section in connection with the diastase-hydrolysis of the parent dextrin itself.

* The glucose was crystallised out from these alcoholic extracts. It proved to be d-glucose. 


\section{Hydrolysis of the Stable Dextrin with Oxalic Acid and with Dicastase.}

When the stable dextrin is hydrolysed with a 2 per cent. solution of oxalic acid under the standard conditions, it is completely converted into $d$-glucose. We here give the result of such an experiment, the glucose being determined by two independent methods.

$$
\begin{array}{ccc} 
& \begin{array}{c}
\text { Glucose from } 100 \text { parts } \\
\text { of dextrin. }
\end{array} \\
\text { 1.-Estimated by increase of sp. gr........... } & 110 \cdot 8 \\
2 .-\quad " \quad \text { from cupric reduction } & \ldots \ldots & 108 \cdot 9
\end{array}
$$

The well-marked 'resting stage' of the products of starch transformations brought about by diastase, when these products have reached an $[a]_{D}$ of $150^{\circ}$ and $R 80$, has already prepared us for the fact that the dextrin, when isolated, has a considerable resistance to the hydrolytic influence of diastase. The observed difference in the rapidity of this action on the dextrin, on the one hand, and on maltodextrin or any of the intermediate transformation products, on the other, is very striking. Whereas solutions of maltodextrin of a concentration of from 5 to 10 per cent. are completely resolvable into maltose by about half an hour's digestion at $50^{\circ}$ with an amount of malt extract corresponding to but 2 or 3 c.c. per 100 c.c. of solution, a dextrin solution requires several hours of similar treatment with ten times the amount of hydrolysing agent before even an appreciable amount of change is produced.

We have made this experiment several times, with every necessary correction, and have found that a solution of the stable dextrin of 7 per cent. concentration, with the addition of malt extract at the rate of 25 c.c. per 100 c.c. of solution, is only hydrolysed to the extent of about 30 per cent. after 48 hours at $55^{\circ}$.

The products of hydrolysis in this case consisted of almost exactly equal quantities of maltose and dextrose, a fact which was shown, not only by the relation of the optical and the reducing properties of the products, but also by the preparation, separation, and estimation of the osazones.

At first sight, it might be considered that the glucose found in this reaction was a secondary product, the dextrin yielding in the first place maltose, which was subsequently hydrolysed to glucose by the enzymes of the malt-extract. This explanation might certainly apply in those cases where an air-dried malt is employed, for an extract of such a malt often contains a transforming agent which, by long continued action, has an appreciable effect in hydrolysing maltose. In this case, however, a kiln-dried malt was employed whose "aqueous 
extract was shown to be incapable of acting on maltose, even after 60 hours digestion at $55^{\circ}$. We must, therefore, regard the formation of maltose and glucose during the hydrolysis of the dextrin as being simultaneous and not successive phenomena, a fact which, in conjunction with their approximately equal production, is of some importance in its bearing on the constitution of the dextrin.

\section{Generalisations and Conclusions.}

When starch is transformed by an active diastase, such as that derived from an air-dried malt, at temperatures below $60^{\circ}$, the reaction proceeds very rapidly until a resting stage is reached corresponding to $[\alpha]_{\mathrm{D}} 150^{\circ}$ and $\mathrm{R} 80$ for the mixed products of change. At this point, these products consist of maltose, and a dextrin which, comparatively speaking, is very resistant to the further action of the hydrolytic agent. This dextrin has a specific rotatory power of $[a]_{D} 197-198^{\circ}$ and, even when obtained in the purest possible state, has a feeble reducing power corresponding to $R 5 \cdot 5$.

Under the mild oxidising influence of mercuric oxide and baryta, the dextrin is converted into a complex carboxylic acid-dextrinic acid.

Under the hydrolytic action of dilute acids, this carboxylic polysaccharide is resolved into $d$-glucose and a residual $\mathrm{C}_{5}$-acid which is identical with the $\mathrm{C}_{5} \mathrm{H}_{10} \mathrm{O}_{6}$-acid obtained either from the acid hydrolysis of the maltodextrinic acids, or from the hydrolysis of the biose acid proceeding from the oxidation of maltose with mercuric oxide.

In the case of maltodextrin and the maltodextrinic acids, on the other hand, the complex is certainly resolvable by diastase into $\mathrm{C}_{12}$-groups only, that is, into maltose.

At first sight, this points to there being a difference in the linkings or spatial relations between the $\mathrm{C}_{12}$-groups and their constituent $\mathrm{C}_{6}$-groups, and since in the case of dextrin and its derivative dextrinic acid there is no selective disposition on the part of diastase to split off maltose rather than glucose, we are justified in regarding the stable dextrin as made up of $\mathrm{C}_{6}$-complexes.*

A consideration of all the facts we have brought forward justifies us in regarding the stable dextrin, from an empirical point of view, as a combination of 39 groups of $\mathrm{C}_{6} \mathrm{H}_{10} \mathrm{O}_{5}$ - and one $\mathrm{C}_{6} \mathrm{H}_{12} \mathrm{O}_{6}$-group or as $40\left(\mathrm{C}_{6} \mathrm{H}_{10} \mathrm{O}_{5}\right)+\mathrm{H}_{2} \mathrm{O}$.

* In pushing this explanation to its ultimate conclusion, we are, however, met with the difficulty that the dinstase of the kilu-dried malt used in these experiments is incapable of hylrolysing maltose. Oue would expect that a hydrolysing agent which could determine the resolution of the dextrin complex either into $\mathrm{C}_{6}$ or $\mathrm{C}_{12}$-groups would also be able to resolve any of the fission products into glucose, but this apparently is not the case. 
Its constitution may, however, be more rationally regarded as a condensation of 40 glucose molecules with the elimination of the elements of 39 molecules of water.

This constitution may be expressed in the following manner, only one of the 38 similar intermediate groups being represented for the sake of brevity.

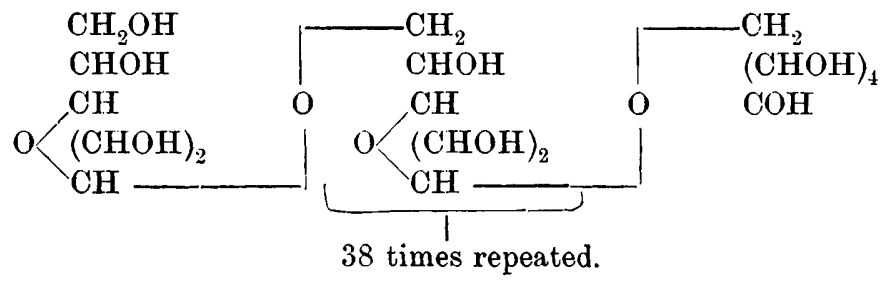

On this view, the constitution of dextrinic acid will be given by converting the terminal right hand group to $-\mathrm{CH}_{2} \cdot[\mathrm{CH} \cdot \mathrm{OH}]_{3} \cdot \mathrm{COOH}$, which is the residue of the $\mathrm{C}_{5} \mathrm{H}_{10} \mathrm{O}_{6}$-acid given by the complete hydrolysis of dextrinic acid with acids.

These complicated constitutional formulæ can be written in an abbreviated form somewhat similar to that employed for the condensed formula of maltodextrin.

$$
\begin{aligned}
& \mathrm{O} \cdot \mathrm{C}_{6} \mathrm{H}_{10} \mathrm{O}_{4} \\
& \mathrm{O}_{37} \cdot\left[\mathrm{C}_{6} \mathrm{H}_{10} \mathrm{O}_{4}\right]_{38} \\
& \mathrm{O} \cdot \mathrm{C}_{6} \mathrm{H}_{10} \mathrm{O}_{4} \cdot \because \\
& \text { Stable dextrin. }
\end{aligned}
$$

$$
\begin{aligned}
& \mathrm{O} \cdot \mathrm{C}_{6} \mathrm{H}_{10} \mathrm{O}_{4} \cdot \\
& \mathrm{O}_{37} \cdot\left[\mathrm{C}_{6} \mathrm{H}_{10} \mathrm{O}_{4}\right]_{35} \cdot \\
& \mathrm{O} \cdot \mathrm{C}_{5} \mathrm{H}_{9} \mathrm{O}_{5} . \\
& \text { Dextrinic acid. }
\end{aligned}
$$

The oxygen atoms on the left in each case represent the 39 oxygen linkings between the 40 groups. The sign $\because$ is again used to indicate the open carbonyl of the terminal group.

We have now to see how far the above views are in consonance with the observed facts.

It is manifest that an ultimate analysis of such substances cannot determine their exact composition. It would, in fact, be quite impossible by a mere combustion to differentiate a dextrin made up of 39 groups of $\mathrm{C}_{6} \mathrm{H}_{10} \mathrm{O}_{5^{-}}$and one $\mathrm{C}_{6} \mathrm{H}_{12} \mathrm{O}_{6}$-group, from one wholly made up of $\mathrm{C}_{6} \mathrm{H}_{10} \mathrm{O}_{5}$-groups, since the carbon percentages are within 0.12 per cent. It is only by such methods as we have described, that is, by examination of the salts of the derivative acids, and a quantitative study of the products of hydrolysis, that we can expect to have any light thrown on their approximate constitution.

Commencing with the dextrinic acid, the calcium salt of an acid of the above constitution should contain 0.30 per cent. of calcium; the actual amount of calcium found in the pure salt was 0.29 per cent. The amount of glucose which, on the above view, ought to be obtain- 
able from free dextrinic acid by complete hydrolysis is 108.2 per cent., and 107.9 per cent. from its calcium salt. The glucose obtained in our experiments from the free acid was in one case 105.9 per cent., and in another 106.2 per cent., whilst the dry calcium salt of the dextrinic acid gave $107 \cdot 2$ per cent.

Turning now to the acid hydrolysis of the dextrin itself, we note that, with the constitution which we have attributed to it, it ought to yield on complete acid hydrolysis 110.8 per cent. of glucose. The actual amount found by one process was 110.8 , and by another 108.9, the error in the second determination being certainly a minus one.

We have seen in a previous paper how the cupric-reducing power of the maltose residue of maltodextrin is approximately that of an equivalent quantity of maltose. In the same way, it appears that the glucose residue, constituting the reducing portion of stable dextrin, also retains the reducing power proper to dextrose, for if we regard, as we are entitled to do from the study of its oxidation products, the stable dextrin as constituted of $39 \mathrm{C}_{6} \mathrm{H}_{10} \mathrm{O}_{5}$ groups and one glucose group, the 'apparent glucose' in this complex, as determined from the actual amount of cupric oxide it reduces, is about $2 \cdot 7$ per cent. This corresponds to an apparent maltose percentage of 5.5 , that is, to an $R$ of $5 \cdot 5$, which is exactly the value expressing the reducing power of the dextrin in a pure state.

It now remains to discuss the bearing of our recent work on the size and constitution of the molecule of starch, or rather that of soluble starch, which differs materially in physical properties from the substance forming the greater part of the starch granule.

The commonly accepted empirical formula for soluble starch, $n \mathrm{C}_{6} \mathrm{H}_{10} \mathrm{O}_{5}$, or $n \mathrm{C}_{12} \mathrm{H}_{20} \mathrm{O}_{10}$, is doubtless correct, since it is not only in accord with numerous combustions made from time to time by different observers, but is also fully confirmed by our own work, described in a previous paper (this vol., p. 307), in which we have accurately determined the amount of glucose which it yields under acid hydrolysis, and also the actual amount of products obtained by diastasehydrolysis.

In our previous writings (Brown and Heron, Brown and Morris, \&c.), we have frequently drawn attention to the fact that the quantitative relations of the maltose and dextrin, occurring in starch transformations which have been brought down to the 'resting stage' by diastase, are in close agreement with the view that the reaction takes place according to the empirical equation represented by

$$
\begin{gathered}
10 \mathrm{C}_{12} \mathrm{H}_{20} \mathrm{O}_{10} \\
\text { Starch. }
\end{gathered}
$$

This is the 'No. 8 equation' of our earlier writings. It assumes vOL. LXXV. 
that the dextrin is a substance without cupric-reducing power, and with an empirical formula of $n \mathrm{C}_{12} \mathrm{H}_{20} \mathrm{O}_{10}$, or $n \mathrm{C}_{6} \mathrm{H}_{10} \mathrm{O}_{5}$. As we now know that the stable dextrin is not altogether free from reducing power, and that its formula cannot be expressed in a simpler form than by $40 \mathrm{C}_{6} \mathrm{H}_{10} \mathrm{O}_{5}+\mathrm{H}_{2} \mathrm{O}$, the above equation requires modifying in such a manner as to show the interaction of $\frac{1}{10} \mathrm{~mol} . \mathrm{H}_{2} \mathrm{O}$ more than the eight molecules indicated. The multiplication of both sides of the equation by 10 , and the introduction of $1 \mathrm{~mol} . \mathrm{H}_{2} \mathrm{O}$ more, brings the theoretical expression in close accord with the facts: thus

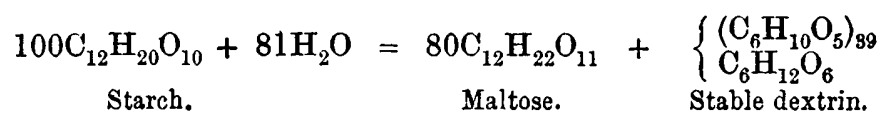

This requires the mixed products of transformation at the close of the reaction to have optical and reducing properties corresponding to $[a]_{\mathrm{D}} 149 \cdot 2^{\circ}, \mathrm{R} 81 \cdot 8$, whilst the old uncorrected expression requires $[a]_{D} 150 \cdot 2^{\circ}, R 80.8$. The experimental values are always very close to $[a]_{\mathrm{D}} 150^{\circ}, \mathrm{R} 80-81$.

It must be borne in mind that the value of $R 81.8$ cannot now be regarded as being quite a measure of the actual amount of maltose present in the products of one of these low transformations, owing to the fact of the dextrin being slightly reducing. The actual amount of free fermentable maltose corresponds to 80.8 per cent., the difference of 1 per cent. being accounted for by the reducing power of the dextrin.

From the quantitative relations of the maltose and dextrin found in the mixed products of starch hydrolysis which have been brought down to the resting stage, it is clear that the size of the starch molecule cannot be less than five times that of the stable dextrin.

The study of the dextrinic acid derived from the dextrin has given us a minimum expression of the size of the dextrin molecule, apparently represented by $39\left(\mathrm{C}_{6} \mathrm{H}_{10} \mathrm{O}_{5}\right), \mathrm{C}_{6} \mathrm{H}_{12} \mathrm{O}_{6}$, which indicates a molecular weight of 6498 .

In the year 1889 (Trans., 55, 462), one of us, in conjunction with G. H. Morris, described certain attempts which we had made to determine the molecular weight of some of the starch derivatives by means of the freezing-point method, and amongst others we examined the stable dextrin prepared from a starch transformation with diastase run down to the 'resting stage.' This dextrin, prepared by alcoholic precipitation, had optical and reducing properties corresponding to $[a]_{\mathrm{D}} 196 \cdot 2^{\circ}, \mathrm{R} 7 \cdot 3$. Its molecular weight, deduced from the mean of a large number of concordant experiments made on the depression of the freezing point of a strong aqueous solution, was 6221 . Although we are less disposed than formerly to base any arguments 
on the molecular weight determinations of these colloids by the freezing-point method, it is certainly remarkable that we should have been led to practically the same conclusion as to the molecular weight of the dextrin by considerations entirely independent of each other.

Granted that the molecular weight of the stable dextrin is 6498 , the complex representing the molecule of soluble starch cannot have a less molecular weight than 32,400 , its empirical formula being represented by $100 \mathrm{C}_{12} \mathrm{H}_{20} \mathrm{O}_{10}$ or by $\left(80 \mathrm{C}_{12} \mathrm{H}_{20} \mathrm{O}_{10}, 40 \mathrm{C}_{6} \mathrm{H}_{10} \mathrm{O}_{5}\right)$. The latter expression connotes the fact that the one-fifth of the molecule which gives rise to the stable dextrin on hydrolysis, differs from the remainder which is directly hydrolysable to maltose. The known properties of soluble starch . would in themselves suggest a very high molecular weight; its highly colloidal nature, the ease with which it can be removed from its solutions by merely forcing them through porous earthenware, and the extremely small influence it exerts on the freezing point* of its solvent all pointing to a very high molecular complexity, a complexity which probably approaches that of some of the proteids.

Since starch is a non-reducing polysaccharide it does not contain free carbonyl groups.

The simplest manner in which it can be expressed constitutionally, with due regard to all the facts, is to consider it as made up of the residues of 80 maltan groups and 40 dextran groups, linked in ring form through oxygen atoms.

On hydrolysis, the dextran complex, constituting one-fifth of the whole molecule, is split off with the formation of the stable dextrin, $39 \mathrm{C}_{6} \mathrm{H}_{10} \mathrm{O}_{5}, \mathrm{C}_{6} \mathrm{H}_{12} \mathrm{O}_{6}$, whilst the maltan portion of the ring is attacked at the oxygen linkings of the $\mathrm{C}_{12}$-groups, the hydrogen ions of the reacting water molecules moving in one direction, and the hydroxyl ions in the other, thus forming, by successive stages of hydrolysis, maltodextrins or " reducing dextrins," $\uparrow$ and finally maltose. $\neq$

We here give a condensed representation of our views on the constitution of the molecule of soluble starch, A representing the dextran residue, and $B$ the four equal maltan residues. Although in

* We found in 1889 (see Brown and Morris, Trans., 55, 465) that the depression of the freezing point of an aqueous solution of soluble starch was extremely small, indicating a molecular weight between 20,000 and 30,000 .

$\dagger$ The term maltodextrin is preferable to that of ' reducing dextrin,' since the latter does not connote the all-important fact that such substances do not contain any stable dextrin residue, but are wholly convertible into maltose by diastase hydrolysis.

$\mp$ The manner in which the activity of the diastase has been previously modified by heat, the time of the reaction, and the temperature at which it takes place, are the principal factors in determining the amount of degradation of the maltan portion of the starch. 
this condensed constitutional formula we indicate the maltan constituents of the molecule as being arranged in four groups, this is not essential to the hypothesis here put forward, for it is possible that the oxygen linkings between the individual $\mathrm{C}_{12}$-groups may all be of

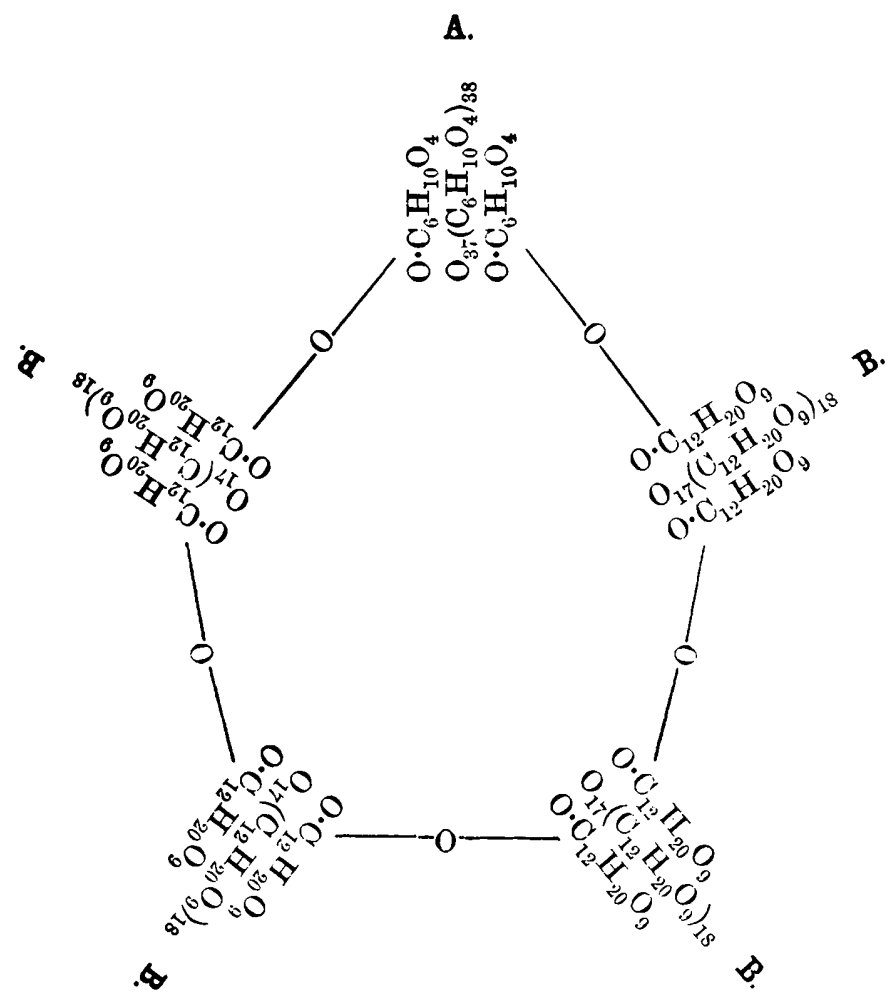

* It will be observed that there are some points of similarity between this constitutional formula for starch and that suggested by Dr. Armstrong in 1880 (see Armstrong's Miller's Elements, p. 658).

the same order, and that the fission due to hydrolysis may occur indifferently at any point of the maltan portion of the chain. The experiments, however, which we described in 1889 (Trans., 55, 469) on the freezing of solutions of high starch products and of transformations arrested at an early stage of hydrolysis, certainly suggest that the early fission products have a molecular complexity about equal to that of the stable dextrin itself; in other words, that the first act of hydrolysis is to divide the starch molecule into five approximately equal parts.

Whilst a consideration of the new facts we have brought forward in these recent papers has led us to very much the same view as that 
held by one of us and Morris ten years ago as regards the size and complexity of the starch molecule, our study of the whole question during the last four years has enabled us to substitute for the tentative hypothesis then put forward one which is perhaps a step nearer the truth, and at any rate has the advantage of being more in consonance with the ordinarily accepted views of the constitution of the carbohydrates.

According to the old view, we pictured the starch molecule as consisting of four complex amylin groups arranged round a fifth similar group constituting the portion of the complex which ultimately became the stable dextrin. It was considered that the first action of the diastase was to liberate these five complexes in the form of non-reducing dextrins, and that four of these differed from the tifth in being hydrolysable by successive gradations down to maltose. At that time, the existence of high, degradable, non-reducing dextrins was considered probable, but further investigation has convinced us that such substances do not exist as separate entities, and that all the fission products of starch hydrolysis are, to some extent, reducing, the extent of this reducing power being dependent on the relation of the end carbonyl group to the size of the complex to which it is attached.

Davy-Faraday Research Laboratory, ROYal INSTITUTION. 